\title{
A Tradição Romanística em Período Medieval: entre práxis e esquecimento
}

\section{Roman Legal Tradition in Medieval Period: between oblivion and praxis}

\author{
Luciene Dal Ri \\ Universidade do Vale do Itajaí, Itajaí - SC, Brasil
}

\begin{abstract}
Resumo: O objetivo deste artigo é analisar o status da tradição romanística nos regimes das fontes do direito, em período medieval. Com esse intuito, estudou-se a experiência jurídica de alguns reinos germânicos, estabelecidos no antigo território do Império Romano, o direito da Igreja, a visão política do Sacro Império Romano Germânico e a influência da Escola de Bolonha. Por meio do método de pesquisa indutivo, observou-se que a tradição romanística atuou em diferentes planos de influência, como fonte primária e subsidiária do direito; transmitindo via costume noções romanas a instituições jurídicas medievais; e influenciando na composição sistêmica de novos sistemas jurídicos.
\end{abstract}

Palavras-chaves: Tradição Romanística. Fontes do Direito. Período Medieval.

\begin{abstract}
To analyze the status of Roman legal tradition in schemes of the sources of law in medieval period, it is the purpose of this article. To that end, it was studied the legal experience of some Germanic kingdoms established in the ancient territory of the Roman Empire, the Church's right, the political vision of the Holy Roman Empire and the School of Bologna. Through the inductive research method, it was observed that the roman legal tradition acted on several levels of influence, as a primary source and a subsidiary; transmitting Roman notions to medieval legal institutions; in addition to observe their influence on systemic composition of new legal systems.
\end{abstract}

Keywords: Roman Legal Tradition. Sources of Law. Medieval Period.

\section{Introdução}

A presença e a importância do direito romano, por meio da tradição romanística, estendem-se muito além dos limites temporais e territoriais do Império Romano, encontrando pleno desenvolvimento na idade média

Recebido em: 04/04/2016

Revisado em: 11/10/2016

Aprovado em: 22/10/2016 
e moderna. Observa-se, por exemplo, que o desenvolvimento da tradição romanística influenciou de forma consistente as experiências jurídicas subsequentes ${ }^{1}$.

Essa influência ocorreu de forma consistente por meio das fontes do direito, moldando as experiências jurídicas medievais, e as caracterizando de forma a contribuir para as suas dinâmicas. As fontes do direito são as formas como o direito se manifesta em sociedade, sendo meios de produção do direito e tendo a função de presidir os diferentes modos de estrutura e sistematização de cada experiência jurídica² .

Como evidencia Orestano, a estrutura organizacional de cada sociedade é por si um fato normativo que atua na formação de outros fatos normativos, sendo inseparável da atuação do regime das fontes do direito (ORESTANO, 1967, p. 99). Nesse sentido, o poder de participação da tradição romanística junto às fontes do direito, delimitando conteúdos, reflete e permite uma importante influência na organização social.

\footnotetext{
${ }^{1}$ Várias são as formas de denominar a estrutura, a organização e a dinâmica jurídica de uma sociedade. Alguns optam por "sistema jurídico", outros por "ordenamento jurídico", neste artigo, por conta da amplitude de modelos jurídicos abarcados, opta-se pela noção de "experiência jurídica". A noção de experiência jurídica, bem evidenciada por Orestano, como uma abstração e produção do pensamento jurídico, modelável de muitas maneiras, em função do que se coloca em evidência e como finalidade, permite tratar da dinâmica das fontes do direito, em suas formas e conteúdo (ORESTANO, 1997, p. 382-396).

2 Opta-se pelo termo "fonte do direito" por representar aquele denominador comum mínimo "[...] tra i vari atti e fatti che nei diversi ordinamenti e nel corso dela storia si sono dimostrati idonei a innovare gli ordinamenti stessi [...]" e me afasto da distinção entre fontes de produção e fontes de cognição, bem como entre fontes-ato e fontesfato (REPOSO, 2009, p. 141 s). Nesse sentido, “A metáfora 'fonte' (pois é de metáfora, claramente, que se trata) continua a nos parecer apropriada precisamente por seu valor metafórico: como as fontes da nossa paisagem física, exprimem bem a essência do fenômeno jurídico enquanto extratos profundos. De fato, repetimos tantas vezes que o direito é realidade radical, ou seja, atinente às raízes de uma sociedade ainda que, na vida cotidiana, manifeste-se em usos de populações, leis dos detentores do poder político, atos da administração pública, sentenças de juízes, praxe de operadores econômicos e assim por diante. $\mathrm{O}$ direito pode ordenar o social porque é realidade com raízes e raízes profundas" (GROSSI, 2008, p. 69). Sobre as fontes do direito e o presidir os diferentes modos de estruturação do direito, ver Villey (2009, p. LXXVIII).
} 
A problemática que fomenta este trabalho concerne à caracterização do diferente status atribuído à tradição romanística, na dinâmica do regime das fontes do direito, no seio de algumas experiências jurídicas medievais. O período abarcado pela pesquisa limita-se da queda do Império Romano do ocidente até o século XII, com o início da Escola de Bolonha, pois a partir de então a autoridade atribuída ao Corpus Iuris Civilis, e as suas interpretações, o evidenciam como fonte primária de muitas experiências jurídicas europeias.

Como evidencia Padoa-Schioppa (2014, p. 19), a crise do Império Romano não significou a crise do seu direito, visto que o direito romano tardo-antigo manteve-se presente, mesmo após a queda do império do ocidente, e constituiu o fundamento de instituições, procedimentos, normas e costumes contratuais que foram transmitidos ao período medieval. Nesse âmbito, busca-se entender os diferentes planos de aplicação da tradição romanística, denotando a variação no regime das fontes do direito, por meio de sua dinâmica de valorização.

Pesquisar sobre a dinâmica das fontes do direito é também delinear a dinâmica política e jurídica da sociedade ${ }^{3}$. A pesquisa sobre as fontes não se baseia então apenas nos textos jurídicos, mas também nos aspectos políticos e sociais, bem como na filosofia e na teoria política, buscando distinguir as teorias que fundamentam o saber jurídico (VILLEY, 2009, p. LXXVIII).

\section{A Alta Idade Média e as Fontes do Direito}

A transição do antigo para o medieval é particularmente complexa, não apenas pelo processo de ruptura e sua pluralidade, mas pela di-

\footnotetext{
3 Nesse contexto, afasta-se a aplicação do conceito "Estado" da realidade antiga e medieval, uso feito por parte da doutrina que, assim como atribui conceitos modernos à realidade antiga e medieval, impõe consequentemente a separação entre direito e religião, desconsiderando que conceitos modernos têm implicações especificamente modernas. A referência é feita em particular neste artigo ao jurista italiano Antonio Padoa Schioppa que se refere com frequência à estrutura e organização administrativa romana como Estado. Sobre Estado, direito e religião romana ver Hegel (1963, p. 178 ss.). Sobre Hegel e positivismo jurídico no direito romano, ver Catalano (1996, p. 146 ss.).
} 
ficuldade de reconstrução de um amplo leque de fontes de pesquisa que permitam delinear de forma mais ampla, a pluralidade política e jurídica em questão. Mesmo com toda a dificuldade, é possível observar textos e costumes provenientes do direito romano na alta idade média, por meio da legislação bárbara ${ }^{4}$, da doutrina e da obra Variae de Cassiodoro (coletânea de cartas e documentos). Autores como Calasso e Padoa Schioppa são claros na presença de uma tradição romanística, muito embora não seja evidente delinear o regime das fontes do direito que a abarca.

Na busca por delinear a dinâmica de variação do status da tradução romanística, dentre as fontes do direito na alta idade média, aborda-se inicialmente e por sua importância, os aspectos jurídicos da doutrina de Santo Agostinho ${ }^{5}$, por encontrar-se nas obras do Santo uma teoria das fontes do direito. A abordagem à teoria de Santo Agostinho ocorre contextualizada pela análise filosófica de Michel Villey, por permitir o necessário diálogo entre direito, filosofia e teologia.

\subsection{A Doutrina Agostiniana das Fontes do Direito}

Para Santo Agostinho, cidadão romano e cristão que vive entre o final do século IV e início do século V, a teoria das fontes do direito desenvolve-se dentro de uma concepção de lei, intrinsecamente ligada ao conceito de justiça (PACIONI, 2004, p. 126 s.) $)^{6}$. Dentro dessa concepção, a fonte última do direito é Deus (por meio da lei eterna ou vontade

\footnotetext{
${ }^{4}$ Como exemplo de diferentes legislações bárbaras, visigoda: Edictum Theodorici (458 d.C.), Codex Euricianus (476 d.C.), Lex romana visigothorum (506/7 d.C.), Codex Revisus (580 d.C.) franca: Lei sálica (488 a 511 d.C.), Lex gundobada (516 d.C.).

${ }^{5}$ Santo Agostinho de Hipona, nasceu em 354 d.C. em Tagaste, cidade romana no Norte da África e morreu em 430 d.C. em Hipona, também cidade romana no Norte da África, muito embora fosse um cidadão romano, manifesta de forma muito mais evidente sua pertença cristã.

${ }^{6}$ Ver também Santo Agostinho. Contra Fausto 22, 27; Cidade de Deus. XIX, 6; Libero Arbitrio I, 1.
} 
divina $)^{7}$, que nos faz conhecer sua justiça por meio de três tipos de leis: a lei da natureza, a lei de Moisés e a lei de Cristo (VILLEY, 2009, p. 97) ${ }^{8}$.

Os três tipos de leis indicados refletem a vontade de Deus, ao expressarem a justiça divina, e são encontrados na Sagrada Escritura, evidenciando que uma sociedade educada nos parâmetros da teoria de Santo Agostinho, ou seja, que busca a vida junto a Deus, "[...] vive convencida de que a única fonte autêntica de direito é a Sagrada Escritura" (VILLEY, 2009, p. 105 ss., ver p. 109 s.)

Observa-se então que a concepção de lei e de justiça do santo reflete o caráter platônico de sua doutrina e enquadra-se na concepção da beatitude da vida humana como vida voltada a Deus e à realidade eterna. Nessa perspectiva, na teoria das fontes do direito de Santo Agostinho é amplamente conhecida a condenação às leis da realidade temporal, entendidas como o direito da cidade terrena e exemplificada no direito romano, despojando-o da auréola de justiça que lhe dava autoridade. Para o santo, a verdadeira justiça (aquela divina), está expressa apenas na lei de Cristo ${ }^{9}$.

A condenação agostiniana ao direito humano (e romano) partia da sua não importância no plano da realidade eterna, muito embora o santo manifeste a expectativa que o direito se torne cristão (e nesse intuito vê-se o desenvolvimento do direito canônico) (VILLEY, 2009, p. 105 ss., ver p.

\footnotetext{
${ }^{7}$ Ver também Santo Agostinho. Contra Fausto, XXII, 27; Cidade de Deus. XIX, 6.

${ }^{8}$ Santo Agostinho também faz referência em seus escritos à relação entre a lei eterna, a lei natural e a lei positiva. Sobre o assunto ver: Rossatto (2015, p. 87 ss.). Ver Santo Agostinho, Contra Fausto, XIX. (VILLEY, 2009, p. 95 ss.): "Na Bíblia, na experiência judaica, no próprio Evangelho, santo Agostinho vai descobrir um novo tipo de justiça, ao qual somente se aplicam estritamente as palavras justiça e direito - um tipo bem diferente do sistema jurídico romano. É dessa forma que será legada à Idade Média uma nova teoria do direito, de suas fontes, de suas fronteiras e de seu conteúdo". O santo indica dois tipos de realidade, aquela temporal e aquela eterna, tais realidades se refletem em dois tipos de homens, os que amam e buscam a realidade eterna e os que amam e buscam a realidade temporal. Aos que amam a realidade eterna será aplicada a lei eterna e aos que amam a realidade temporal será aplicada a lei temporal. Ver também De Capitani (1994, p. 113), em base ao livro De libero arbitrio, I, V, 11 ss. e I, XV, 32.
}

${ }^{9}$ Ver Santo Agostinho, La città di Dio, II, 16-29 (VILLEY, 2009, p. 93) 
109 s. $)^{10}$. As críticas ao direito humano (e romano) eram fundamentadas na não conformidade de suas normas com a fé cristã, tornando injusta muitas de suas instituições e comprometendo toda a experiência jurídica. Entendia o santo que onde não há justiça (conforme a fé cristã), não há direito legítimo ${ }^{11}$.

A visão crítica ao direito romano, porém, não inspira Santo Agostinho à desobediência a tais leis, por serem úteis à ordem pública e à segurança (trazendo dessa forma certa justiça, mesmo que embrionária) e por serem emanadas de um poder que de fato existe e recebe sua autoridade por meio da Providência Divina (pois tudo o que acontece é obra de Deus) (VILLEY, 2009, p. 91 s.; DE CAPITANI, 1994, p. 112) $)^{12}$.

Recorda-se que a doutrina agostiniana muito embora condene o direito humano, em particular o direito romano (por simbolizar a temporalidade diante do direito divino), deixa espaço para o seu uso no silêncio dos textos bíblicos, principalmente diante de um "direito da Igreja" pouco desenvolvido e ainda frágil ${ }^{13}$. Nesse contexto, não se observa na alta idade média a incompatibilidade profunda entre a Igreja e o direito romano,

\footnotetext{
10 "há vestígios de direito romano, há costumes populares, sobrevivências e usos de fato; eles tinham motivos legítimos para sobreviver mesmo no sistema agostiniano". Quanto às fontes do direito canônico durante a Alta Idade Média, ver: Musselli (1992, p. 23-32).

${ }^{11}$ Santo Agostinho. De libero arbitrio libri tres. I, V, 11: "Non ergo lex iusta est, quae dat potestatem uel uidatori, ut latronem, ne ab eu ipse occidatur, occidat, uel cuipiam uiro aut feminae, ut uiolenter sibi stupratorem iuruentem ante inlatum stuprum, si possit, interimat. Nam militi etiam iubetur lege, ut hostem necet, a qua caede si temperauerit, ab imperatore poenas luit. Num istas leges iniustas uel potius nullas dicere audebimus? Nam lex mihi esse non uidetur, quae ius nun feurit." No mesmo sentido ver também Ibidem, I, V, 13; I, VI, 14 e 15.

${ }^{12}$ Em base ao livro De libero arbitrio, I, XV, 32: "Ma ció no significa che la legge temporale non possa esistere. Essa regolerà le realtà che non possono dirsi nostre se non ad tempus, temporaneamente, e che sono utili "per conservare la pace e la convivenza humana".

${ }^{13}$ Opta-se aqui pelo uso do termo "direito da Igreja" pelo tardo desenvolvimento do direito canônico que até meados do século XII não se distinguia da teologia (VILLEY, 2009, p. 115).
} 
como tradição romanística, sendo possível observar o seu uso não apenas pela sociedade, mas pela própria Igreja ${ }^{14}$.

\subsection{A Tradição Romanística nos Reinos Bárbaros: a pluralidade de concepções}

Em paralelo à teoria agostiniana, pode-se recavar que as normas dos nascentes reinos bárbaros, ao considerarem o direito que regia as populações locais e que tinha sido incorporado ao costume, recepcionam mesmo que parcialmente os textos (legislativos e doutrinários) e as práticas de direito romano.

A distância entre a cultura germânica e aquela romana, também em suas experiências jurídicas é particularmente evidenciada por Calasso, ao afirmar que não houve convivência pacífica entre os diferentes sistemas jurídicos.

Due sistemi giuridici si trovavano in contatto, distanti fra loro non soltanto per la diversità dei cardini fondamentali sui quali poggiavano, ma, sopra tutto, per il grado di maturazione. Era fatale che il contatto si trasformasse in un contrasto profondo, quanto può essere profondo un contrasto di civiltà. (CALASSO, 1954, p. 119) ${ }^{15}$

\footnotetext{
14 “A Igreja romana foi inclusive o conservatório dos textos jurídicos romanos; vários papas da época carolíngia (principalmente Nicolau I) recomendaram seu uso. Aliás, as compilações jurídicas romanas foram, por muito tempo na Idade Média, consideradas obra desses imperadores cristãos cuja função sagrada foi descrita na própria Cidade de Deus. O Código não se iniciava pela invocação da Santa Trindade? A imagem de Justiniano não figurava nos vitrais das catedrais? Durante muito tempo foi nesse sentido e sob a égide do cristianismo que os glosadores apresentaram sua mercadoria" (VILLEY, 2009, p. 112 e 118).

15 Também para Le Goff, as normas bárbaras não devem causar ilusão, pois eram muito primitivas, tendo sido a forte influência do direito romano a manter a Europa dentro de certos parâmetros jurídicos. "É até o caso do edito do ostrogodo Teodorico o Grande, último herdeiro verdadeiro da tradição romano no Ocidente. [...] Esta legislação bárbara sobre as ruínas do direito romano prolongou, apesar de tudo, uma Europa do direito na Alta Idade Média” (LE GOFF, 2007, p. 48).
} 
Ma se la distanza che separava la civiltà germanica dalla romana nella concezione dello Stato e del diritto era già grande, ancora più grande si rivelava nei vari campi del diritto privato. Con questa differenza: che, mentre la materia pubblicistica è, per la sua stessa natura e funzione, la più aperta e sensibile agl'influssi, e quindi più rapida ad assimilare e a trasformarsi - nè, infatti, è possibile calcolare quanto debba avere influito sia pur quel poco ch'era rimasto in piedi dell'antica amministrazione romana sulla mentalità di quella minoranza di barbari che, ignorando perfino cosa fosse una città fondavano un regno in questa terra di città, e furon costretti dalla loro stessa imperizia ad affidarsi alle classi colte della popolazione soggiogata per una elementare organizzazione amministrativa - il campo dei rapporti privati è, al contrario, più chiuso alle influenze esterne, fortemente conservatore e perciò più torpido nell'assimilare elementi da altri sistemi giuridici, meno facile alle transformazioni radicali. (CALASSO, 1954, p. 125 s.)

Muito embora Calasso se refira a dois sistemas jurídicos, o "romano" e o "germânico", Padoa Schioppa (2014, p. 29) evidencia que mesmo com "aspectos fundamentais" comuns, como a oralidade e as regras consuetudinárias, pois eles não conheciam a escrita, não havia "uniformidade plena" do direito entre os povos germânicos. A análise de leis de diferentes povos germânicos, entre os séculos VI e IX, denota diferenças significativas, intercâmbio e influência recíproca.

A fixação territorial e a criação de reinos germânicos independentes, onde existiam populações com outra cultura, criou um problema de como lidar com as diferentes concepções jurídicas. A solução encontrada foi de manter a distinção entre os modelos jurídicos germânicos e a tradição romanística em muitos aspectos, não evitando, porém, a permeabilidade entre ambas.

[...] o direito do Império Romano tardio antigo teve influência, e não pouca, sobre os ordenamentos públicos e sobre o próprio direito privado dos germanos, a partir de então saídos do nomadismo originário e estavelmente implantados em um território.

Assim tem início um período que se estende por quase seis séculos, até o fim do século XI, durante o qual o direito romano remanes- 
cente coexiste e se entrelaça de modo variado, no interior dos reinos germânicos da Europa ocidental, com os costumes germânicos, onde quer que eles sejam registrados por escrito a partir do século VI, na maior parte das vezes, em latim. (PADOA SCHIOPPA, 2014, p. 13 e 30$)$

A Igreja e a população mantém a tradição romanística, como uma importante referência e fonte do direito, consolidando-a como fundamento de institutos e normas dos reinos bárbaros em diferentes planos: tanto como influência na prática dos institutos jurídicos (costumes), devido ao forte enraizamento na vida social, quanto pela influência crescente dos princípios romanísticos sobre os legisladores dos reinos bárbaros, além de seu caráter subsidiário ${ }^{16}$.

A própria noção de legislação e de codificação não é típica da cultura germânica, mas se fez presente nela por meio da tradição romanística, contrapondo-se muitas vezes a tradição oral daqueles povos (CALASSO, 1954, p. 124) ${ }^{17}$.

A tradição romanística nas experiências jurídicas dos reinos bárbaros foi maior entre os visigodos, os ostrogodos e os longobardos, do que entre os burgúndios ou os francos, como se observa nas legislações emanadas nos diferentes reinos. ${ }^{18}$ Tal fato denota a pluralidade política e

\footnotetext{
${ }^{16}$ Evita-se entrar no debate sobre a "pessoalidade da lei" no direito bárbaro, visto que as fontes não são claras sobre o assunto e existe debate na doutrina (CALASSO, 1954, p. 109 e 124). No mesmo sentido, Padoa Schioppa: “A Igreja exerce seu magistério e, por meio dele, um papel fundamental de civilização, papel religioso e pastoral, mas também civil e político. E contribui para transmitir a sociedade civil muitas regras jurídicas de derivação romanística que ela adotara, bom como e, sobretudo, o inestimável patrimônio da cultura antiga grega e romana que chegou até nós e do qual só possuímos aquilo que foi transcrito nos códices de pergaminho por clérigos e monges da Idade Média." (PADOA SCHIOPPA, 2014, p. 13; GARZÓN, 2006, p. 523).

${ }^{17}$ Especialmente nota 29 com a passagem de Paulo Diácono, Hist. Longob., IV, 44.

${ }^{18}$ Como exemplo de diferentes legislações bárbaras, visigoda: Edictum Theodorici (458 d.C.), Codex Euricianus (476 d.C.), Lex romana visigothorum (506/7 d.C.), Codex Revisus (580 d.C.); franca: Lei sálica (488 a 511 d.C.); burgúndia: Lex Gundobada (516 d.C.), Lex Romana Burgundionum (532 d.C.); longobardo: Edito de Rotario (643 d.C.). Os editos que regulavam o direito dos ostrogodos limitava-se tendencialmente a respeitar o foedus realizado com Zenon, imperador do oriente, segundo Garzón (2006, p. 530).
} 
jurídica típica da Europa, após a queda do Império Romano do ocidente e a diferente forma de adequação do espírito germânico à realidade da população conquistada.

No território de dominação visigoda ${ }^{19}$, por exemplo, o rei bárbaro Teodorico II (453-466) emanou o Edictum Theodorici (458 d.C.), norma escrita em latim, que se dirigia aos romanos e aos bárbaros (considerando as duas populações presentes no território e sem distinção de "pessoalidade da lei”) e acolhera, sem mencionar sua procedência, elementos de várias obras jurídicas romanas como das constituições imperiais, presentes no Codex Theodosianus (438 d.C.) ${ }^{20}$ e posteriores a ele, das Instituições de Gaio, das Sentenças de Paulo e do livro De officio proconsulis de Ulpiano $^{21}$.

Em norma posterior, o rei visigodo Eurico (466-484 d.C.) emanou o Codex Euricianus (476 d.C.) que mesmo promovendo algumas instituições jurídicas germânicas, refletia concepções de direito romano pós-teodosiano $^{22}$. A Lex romana visigothorum, conhecida como o Breviário de Alarico (506/7 d.C), também exemplifica a forte influência romana, por meio de constituições imperiais e da iurisprudentia romana, muito embora provavelmente tenha tido finalidade apenas didática e não normativa (GARZÓN, 2006, p. 525) ${ }^{23}$.

\footnotetext{
${ }^{19}$ Provença e Aquitânia (Sul da Gália e Barcelona).

${ }^{20}$ Código oficial do Império Romano do Oriente, feito sob o Imperador Teodósio (408450 d.C.), mas também adotado por Valentiano III (425-55), Imperador do ocidente.

${ }^{21} \mathrm{O}$ Edito de Teodorico (Edictum Theodorici) é um conjunto de 154 disposições que regulavam os mais variados âmbitos da vida social, tratando tanto de temas de direito privado quanto de direito público. Não adentrarei aqui o debate sobre a autoria do texto, atribuída por Piette Pithou na sua edição do texto (1579) ao rei ostrogodo Teodorico o Grande (474-526) que assentou seu reino na península itálica; mas também atribuída a Teodorico II (453-466): Rasi (1956, p. 349); Vismara (1956, p. 49-90); Falaschi (1966). Não se adentra nem mesmo na invasão muçulmana do século VIII que trouxe nova configuração política e jurídica às comunidades ibéricas.

${ }^{22} \mathrm{O}$ Codex regula questões de direito penal e civil e segundo Surgik, pode ser entendido como fruto de uma escola jurídica tardia (SURGIK, 2002, p. 55).

23 A experiência jurídica ostrogoda, por exemplo, parece aplicar o princípio da personalidade do direito, diferenciando o as leis a serem aplicadas entre romanos e bárbaros. Os longobardos também se distinguem no que tange ao seu patrimônio jurídico.
} 
Importante evidenciar, no que tange ao regime das fontes do direito, que além da forte influência dos textos de direito romano, as situações não reguladas no edito visigodo seriam reguladas pela tradição romanística, bem como as relações entre o reino ostrogodo e o Império Romano do Oriente eram regidas pelo que Calasso denomina de ius commune (CALASSO, 1954, p. 77).

O processo de codificação observado por meio de edicta, codices e leges denota a forte presença das normas escritas, provenientes de reis com a intervenção de concílios, mas sem o envolvimento direto de assembleias populares.

As normas escritas e impostas pelos reis bárbaros, muito embora apresentassem influência romana, tinham fortes características germânicas, e eram contrastadas por seus costumes. Nesse sentido, Padoa Schioppa denota que uma segunda fase da legislação visigótica, em finais do século VI, apresenta maior originalidade ao modificar o código de Eurico, introduzindo elementos da tradição nacional visigoda e germânica (PADOA SCHIOPPA, 2014, p. 31).

Evidencia-se então o papel fundamental do costume, como fonte do direito, durante a alta idade média, pois mesmo que as leis escritas dos povos germânicos impliquem em inovação e incluam normas instituídas pelos reis que as promulgaram, observa-se fortemente o elemento consuetudinário, alimentado pela ausência de ampla legislação e pelo próprio desinteresse totalizante do poder político em relação à vida social.

A permeabilidade de conceitos e normas, sistemáticas e institutos, entre as duas experiências jurídicas pode ser evidenciada como um processo de vulgarização da tradição romanística, ou ser identificada como a formação de novos sistemas jurídicos, que se adequam às nascentes necessidades sociais e são baseados em experiências preexistentes ${ }^{24}$.

O Edictum longobardorum (634 d.C.), do rei longobardo Rotário, é um modelo de legislação bastante peculiar, no qual mesmo podendo observar a influência romana, é ainda mas forte a influência germânica, dando um novo perfil à legislação bárbara.

${ }^{24}$ Sobre a vulgarização e o direito novo ver Brunner (1880, p. 113); Calasso (1954, p. 58, 63 e 107 s) e Garzón (2006, p. 531 ss); Padoa Schioppa (2014, p. 13). 
Esses são os séculos nos quais o costume domina o campo entre as fontes do direito, até dar vida a novas e complexas instituições, que não podem ser classificadas nem como romanas nem como germânicas. [...] Mesmo em meio à extraordinária variedade dos costumes locais, muitos elementos fundamentais comuns subsistem nos direitos da Alta Idade Média europeia, decorrentes tanto da fé religiosa comum quanto das condições análogas de vida de povos e de sociedades predominantemente rurais e militares. (PADOA SCHIOPPA, 2014, p. 13)

O uso de textos e noções de direito romano como fonte para textos normativos de outras experiências jurídicas não afasta o questionamento do seu uso como fonte primária, bem como a hierarquia das fontes existentes. Nesse contexto, denota-se uma hierarquia das fontes do direito que dá hegemonia às normas escritas do direito próprio de cada reino com status subsidiário às normas provenientes da tradição romanística (GARZÓN, 2006, p. 527).

Porém, a incompletude dessas normas, observada por meio das 154 disposições do Edictum Theodorici, que nem de longe regulavam os diferentes aspectos da vida em sociedade, e, ao mesmo tempo, o silêncio em relação às demais fontes, permitem creditar forte importância à tradição romanística, muito embora amplamente cotejada pelos institutos jurídicos germânicos ${ }^{25}$.

\section{O Corpus Iuris Civilis antes da Escola de Bolonha: entre uso e esquecimento}

Com a confecção da obra legislativa do imperador Justiniano, no decorrer do século VI, pode-se questionar se houve maior influência da tradição romanística sobre o direito aplicado nos reinos de origem bárbara, durante a alta idade média. A questão é complexa e denota-se que a doutrina não é pacífica quanto ao (des)conhecimento e uso ou influência do Corpus iuris civilis antes da escola de Bolonha.

${ }^{25}$ Sobre o espírito do direito germânico, ver Calasso (1954, p. 124). 


\subsection{O Debate Doutrinário}

Como denota Calasso (1954, p. 82 s. $)^{26}$, com a reunificação da península itálica ao Império Romano (do Oriente), Justiniano teria emanado uma constituição específica (pragmatica sanctio) em 13 de agosto de 554 para a promulgação da sua compilação "per partes Italiae". As demais províncias do império (ocupadas pelas milícias bárbaras) tinham rompido o vínculo com o império durante o $\mathrm{V}$ século e permaneceram apenas sob a influência do direito romano teodosiano (ou pré-Justiniano). Calasso evidencia que mesmo com a promulgação itálica da obra de Justiniano, o direito teodosiano manteve ainda forte influência sob aquele território.

Calasso (1954, p. 102) afirma que na parte itálica que permaneceu ligada à Bisâncio, sobreviveu o estudo do direito romano, com o acolhimento da obra de Justiniano e da legislação posterior " [...] che formò l'ideale tratto d'unione fra le antiche scuole imperiali di diritto e le grandi scuole italiane, che si affermeranno nel corso del secolo XII e alle quali spetterà il compito glorioso di diffondere il diritto romano in Europa".

No mesmo sentido, Padoa-Schioppa, defende o conhecimento e uso da compilação de Justiniano na Itália desde o período bárbaro. O autor italiano cita como exemplo a Summa Perusina (século VIII), na qual observa-se "em breves proposições o conteúdo do Código justiniano e que foi utilizada na práxis judiciária da Sabina até o início do século XI". (PADOA SCHIOPPA, 2014, p. 50). Tal constatação permite reforçar o entendimento do período medieval e particularmente da alta idade média, não como um período de trevas, mas como de 'luzes esparsas', onde o conhecimento e o uso do Corpus Iuris Civilis não ocorria com mais frequência devido às dificuldades culturais, como a influência germânica, a compreensão dos textos e do método de estudo.

Para Maruotti, porém, houve o 'esquecimento' da obra de Justiniano após a sua morte, no século VI, até o século XII quando a descoberta dos manuscritos conduziu à formação da escola de Bolonha.

\footnotetext{
${ }^{26}$ A citada 'reunificação' não durou muito tempo, tendo iniciado a sua dissolução com a invasão longobarda de 568. Alguns territórios itálicos mantiveram-se, porém ligados à Bisâncio (como a Sicilia, a Sardenha e a Laguna Vêneta), ressentindo de forma fragmentária a influência germânica.
} 
Dopo la morte di Giustiniano, verificatasi nel 565 d.c., neppure le aree dell'Italia bizantina (parti della Puglia e della Calabria, Napoli, Amalfi, Gaeta, la Sardegna, la Sicilia, l'esarcato, l'estuario di Venezia, l'Istria, la Dalmazia) conservarono memoria della Compilazione nel suo complesso, specie quanto all'uso pratico. A causa della dificoltà di comprensione dell'elegante latino classico da parte di una popolazione sì di língua latina, ma ormai culturalmente imbarbarita, i Digesti caddero in completo oblio già nel VI secolo e fino al XII, quando la riscoperta' dei manoscritti condusse alla formazione della Scuola bolognese. (MARUOTTI, 2001, p. 11)

A densidade das fontes e dos argumentos de Calasso e de Padoa-Schioppa acaba por ofuscar a visão de Maruotti, muito embora esse tipo de concepção seja ainda bastante difusa. Muito embora exista o debate quanto ao estudo e uso da compilação de Justiniano, durante a alta idade média, não se discute que a posterior evidenciação de seus textos em território itálico é algo mais do que uma mera coincidência.

\subsection{A Tradição Romanística no Império Carolíngio}

Com a unificação de parte dos reinos de origem bárbara, no Império Carolíngio, muito embora tenha se revivido atributos políticos romanos, como a universalidade do poder político do imperador, não necessariamente fortaleceu-se a tradição romanística em suas legislações. Observa-se, por exemplo, que as intervenções legislativas de Carlos Magno e de seus sucessores não necessariamente substituíram as leis dos reinos que sucumbiram ao novo império. Vale ressaltar que durante os séculos IX ao século XI a tradição romanística foi conservada junto às populações latinas, mais pela via consuetudinária do que por meio da lei escrita. A Igreja também não se afastou dessa tradição, mantendo-a como uma importante referência e fonte do direito (PADOA SCHIOPPA, 2014, p. 38 s. e 49).

As maiores polêmicas e resistências em relação aos textos romanos pela Igreja ocorreram apenas a partir do século XI, quando os textos romanos foram recepcionados em âmbito político e jurídico com convicção de universalidade e tiveram um forte papel na experiência jurídica do Sacro Império Romano Germânico. (VILLEY, 2009, p. 118; HESPANHA, 
2009, p. 141). A valorização do estudo do direito romano e de sua tradição romanística não descartou, porém, os direitos próprios de reinos e de cidades fundadas em tradições jurídicas romanas, canônicas e germânicas (HESPANHA, 2009, p. 142).

\subsection{A Escolástica e a Nova Forma de ver o Direito}

O contexto econômico presente nas cidades europeias, florescentes a partir do século XI, torna mais flexível a estrutura e a mobilidade social, permitindo certo desenvolvimento à noção de homem, como indivíduo, e à sua distinção em base às próprias escolhas e não à estrutura social. A mudança social ocorre permeada pelo desenvolvimento do humanismo cristão e faz-se presente nas incipientes escolas. Evidencia-se no estudo e reflexão cristã a natureza humana e a vida terrena, buscando na cultura antiga inspiração para os novos tempos ${ }^{27}$. A profunda diferença entre os contextos sociais e políticos evidenciam, porém, que muito embora a cultura antiga sirva de inspiração, ela não oferece soluções que possam ser prontamente aplicadas ao contexto social medieval.

Basta considerar que a concepção medieval do mundo é permeada pela ideia de ordem universal, abrangendo homens e coisas, dentro de uma orientação voltada para a aproximação ao Criador, como fim último. Nesse sentido, o direito cristão e toda a organização social tinham como fundamento a ordem divina da criação ${ }^{28}$. A consciência das dificuldades de transposição levou à busca por novas atitudes e possibilidades espelhadas no passado ${ }^{29}$.

\footnotetext{
${ }^{27}$ No século XII inicia-se o movimento de humanismo escolástico, com a valorização de estudos e reflexões sobre o homem e sua natureza. Sobre inspiração antiga e inovação medieval nas cidades, ver Le Goff (2007, p. 145 ss.)

${ }^{28}$ A ordem social trazida por Santo Agostinho e que permeia o período medieval era composta de três classes/funções: o sacerdote, o guerreiro e o servo (trabalhador braçal). Como bem evidencia Hespanha essa era uma fórmula muito antiga (tem-se traços na cultura indo-europeia) de representar a diversidade de status pessoais dentro da sociedade (HESPANHA, 2009, p. 101 s. e 112).

29 "Há uma consciência da redescoberta adaptada a um novo contexto". SALGADO, 2011, p. 20 s. MORRIS, 2004, p. 160. Como referência de novos parâmetros de reflexão pode-se citar Pedro Abelardo (Reino da França, 1079-1142).
} 
A busca pelo antigo com a consciência da necessidade de inovação faz-se presente no que concerne também ao direito e à dinâmica de suas fontes, com a "redescoberta" e evidência da tradição romanística, em pleno século XII, principalmente por meio da compilação de textos de Justiniano, posteriormente chamada de Corpus iuris civilis ${ }^{30}$.

A influência e a importância do "direito romano", como tradição romanística, como fonte do direito na experiência jurídica europeia, a partir do século XII, é muito forte e ocorre de forma não homogênea no tempo. Nesse sentido, Hespanha ${ }^{31}$ propõe a sua compreensão por meio de diferentes fases no regime das fontes do direito. A dinâmica das fontes é contextualizada, na visão do autor português de forma sociopolítica, evidenciando as transformações da concepção de homem e de sociedade, bem como suas continuidades e descontinuidades específicas nas experiências jurídicas.

O regime das fontes do direito é proposto por Hespanha (2009, p. 245, nota 283) em três fases, entre o período medieval e o moderno na Europa. As fases propostas pelo autor português evidenciam a importân-

${ }^{30} \mathrm{O}$ Corpus fundamenta a tradição romanística considerada como "uma formação de valor europeu, que, sem limites temporais e territoriais definíveis com exatidão, se vai constituindo em um corpo mais ou menos flutuante, porém, compacto no fundo, de doutrinas jurídicas" (ORESTANO, 1977, p. 502). Como bem evidencia Mario Talamanca (1990, p. 5), o papel do Corpus iuris civilis na história do direito europeu foi além do modelo de estudo do direito do ponto de vista científico, e abarcou os fundamentos e os limites da casuística, constituindo uma parte do direito vigente, principalmente no âmbito do direito privado.

${ }^{31}$ Manuel Hespanha foi professor e pesquisador português, historiador do direito, de matriz foucaultiana. A abordagem do autor baseia-se na concepção do direito no "seio dos processos sociais (como o da instauração da disciplina social)", bem como evidencia a produção do direito em seus valores e textos, propondo um regime das fontes do direito durante o período medieval. O autor português pressupõe que o direito da Europa foi um direito comum "[...] em que alguns estilos e especificidades locais apenas se destacavam sobre um esmagador fundo de características partilhadas." (HESPANHA, 2009, p. 19 e 38 ss.). Cabe evidenciar que na obra do autor português aqui considerada encontra-se com frequência a referência às ideias de Orestano no que tange ao direito romano e à tradição romanística (em base à mesma obra citada nesta pesquisa) e às ideias de Villey (em base à mesma obra citada nesta pesquisa) no que tange às concepções das estruturas sociais e políticas medievais. 
cia do 'direito romano' em oito séculos de vigência a partir do século XII, desconsiderando a presença anterior da obra de Justiniano.

A primeira corresponde aos séculos XII e XIII e é caracterizada pela redescoberta e preponderância do 'direito romano' e do direito canônico sobre todas as outras fontes do direito que lhe fossem concorrentes e cuja validade só era admitida desde que não estivesse em contraste com a norma de direito comum (ius commune).

A segunda fase estende-se do século XIV ao final do século XVII e caracteriza-se por meio da afirmação de direitos próprios (iura propria) como fonte primária dos ordenamentos particulares, cujo valor se equilibra com o direito comum (ius commune).

A terceira fase ocorre durante o século XVIII e particularmente o século XIX, e é caracterizada pela independência completa do direito dos reinos, que se torna a única fonte do direito. Nesse período o ius commune e o 'direito romano' passam a ser concebidos como fontes de direito de caráter subsidiário. (HESPANHA, 2009, p. 245)

As fases propostas pelo autor não são estanques ou isoladas, mas carregadas de continuidades e descontinuidades, baseadas em concepções políticas e jurídicas, mais do que nas necessidades sociais, no favorecimento e na resistência ao estudo e aplicação dos textos de direito romano, bem como de suas noções.

Observa-se na dinâmica histórica do regime das fontes do direito, trazido pelo autor português, a prevalência do sistema de fontes do direito a partir do século XII, deixando de lado as experiências jurídicas fortemente influenciadas pela tradição romanística e religiosa na alta idade média.

Ao considerar como parte do regime das fontes do direito apenas os sistemas desenvolvidos a partir da revolução cultural do século XII, a visão de Hespanha demonstra-se, portanto e de certa forma, muito ligada à tradição romanística por meio do Corpus iuris civilis e do movimento escolástico. 


\section{A Escola de Bolonha e a Autoridade dos Textos de Direito Romano}

Com a Escola da Bolonha, a compilação de Justiniano é considerada aos olhos dos juristas da Europa continental como o ius-direito em absoluto, e conforme a vontade do próprio Justiniano, que pretendia que sua obra substituísse todas as demais fontes do direito e que fosse aplicada em sua totalidade.

A tradição romanística ganha então nova vida no regime de fontes do direito, graças à valorização da amplitude, método casuístico e detalhamento de institutos jurídicos, bem como da sistemática do conjunto de obras do Corpus Iuris Civilis. Tais características permitem amplo estudo e interpretações que acabam por fundamentar grande parte das ciências jurídicas da Europa continental.

Las vicisitudes de la interpretación del Corpus iuris constituyen una especie de cañamazo ideal de essas ciencias jurídicas, y sin ser tampoco el único aspecto bajo el que pueden ser estudiadas, proporcionan una de la mejores claves para la comprensión de su desarollo. La tradición del Corpus iuris, por su relativa constancia y omnipresencia, representa una especie de coordenada máxima que permite establecer y diferenciar, de tiempo en tiempo y de lugar en lugar, los movimientos del derecho y de las doctrinas a través de su posición frente a ésta. Y tal relación está entre las más significativas e iluminadoras para la valoración de las orientaciones fundamentales de cada experiencia y en cada tiempo y, por lo tanto, también en el nuestro. (ORESTANO, 1967, p. 493) ${ }^{32}$

A revitalização da tradição romanística, na Itália e na Europa, liga-se indiscutivelmente à inspiração colhida na cultura antiga pelo humanismo do século XII e permite a sua colocação como "[...] fonte capital do novo direito comum que dominará a cena do direito do continente até o fím do século XVIII.” (PADOA SCHIOPPA, 2014, p. 19).

${ }^{32}$ Evita-se aqui o debate abordado ibidem por Orestano sobre a concepção dos textos justinianeus (Corpus Iuris Civilis) como ius romanum ou tradição romanística. 
O fundamento da legitimidade e autoridade dos textos de direito romano, nesse período, também causa dissenso na doutrina. Orestano afirma que a vigência do Corpus iuris civilis como "direito absoluto", durante o período medieval, está fundamentada principalmente na autoridade de Justiniano e na afirmada continuidade entre os impérios, bem como na sua forma sistematizada e no método casuístico, por meio do qual o estudo e a prática do direito são desenvolvidos e expostos, permitindo modelos para os negócios jurídicos medievais (ORESTANO, 1977, p. 495).

A concepção de Villey (2009, p. 119) e Padoa-Schioppa (2014, p. 62), sobre a recepção e valorização dos textos de direito romano, demonstra-se mais voltada, porém, para as insuficiências do direito até então desenvolvido ("direito cristão") e as necessidades práticas econômico-comerciais do século XI e XII.

Por mais simpatia que eu tenha pela história filosófica, não vejo como evitar, para explicar o nascimento da escola bolonhesa, a invocação de necessidades práticas. E também a lembrança das insuficiências do sistema jurídico oriundo da justiça cristã: este, como vimos, tinha o defeito de ser vago e exigente demais. [...] O direito cristão talvez bastasse, poderíamos pensar, para comunidades rurais, senhoriais, patriarcais, para grandes famílias, para grupos feudais restritos. (VILLEY, 2009, p. 119)

O direito cristão medieval não supria as necessidades práticas da sociedade em mutação, e apresentou o modelo da experiência jurídica romana, como sistema conhecido que fornecia alguma assistência. A recepção mais ampla das noções de direito romano seria então observada com a redescoberta dos textos de Justiniano no norte da Itália e com o nascimento da escola de Bolonha (VILLEY, 2009, p. 118).

A recepção dos textos de direito romano é trazida por Hespanha (2009, p. 141) sob um ângulo muito mais próximo ao de Orestano, evidenciando a convicção de universalidade no direito do Império Carolíngeo e no Sacro Império Romano Germânico. A importância da recepção do "direito romano" nesse período, não pode ser menosprezada, diante do contraste entre a tradição romanística e a experiência jurídica germânica 
na alta idade média, pois "[...] os costumes gerais ou locais dos vários povos europeus (iura propria) contrastavam fortemente, em muitos domínios, com o direito romano"33.

Hespanha desconstrói a perspectiva de recepção proposta por Villey, de que a recepção do direito romano seria fruto das formas de vida econômica em desenvolvimento na Europa.

A este novo tipo de relações econômicas seriam necessárias três coisas no plano jurídico - um direito estável, que garantisse a segurança jurídica e institucional necessária à previsão e ao cálculo mercantil, um direito único, que possibilitasse o estabelecimento de um comércio inter-europeu, e um direito individualista, que fornecesse uma base jurídica adequada à actividade do empresário, livre das limitações comunitaristas que os ordenamentos jurídicos medievais tinham herdado do direito germânico. O direito romano constituiria, precisamente, um ordenamento jurídico dotado de todas estas características: a sua abstração (i.e., o facto de as situações visadas pelas normas estarem nelas descritas através de formas muito estilizadas e, portanto gerais) opor-se-ia ao casuísmo dos direitos da Alta Idade Média; depois, era aceito como direito subsidiário comum a todas as praças comerciais europeus, constituindo uma língua franca de todos os mercadores [...]. Por último, os grandes princípios dos sistemas jus-romanista coincidiriam, no fundamental, com a visão capitalista das relações mercantis - liberdade de ação negocial, garantida pelo princípio da autonomia da vontade; possibilidade de associações maleáveis e funcionais, facultada pelas figuras romanísticas da personalidade jurídica ou colectiva (universitas, corpora, etc.); extensão ilimitada do poder de lançar os bens e capitais no giro mercantil, facultada por um direito de propriedade que desconhecia quaisquer limitações sociais ou morais ao uso das coisas. (HESPANHA, 2009, p. 144 s.)

\footnotetext{
${ }^{33}$ Sobre as diferenças entre direito recebido e direito tradicional, ver Hespanha (2009, p. 142 e 158 ss.). As questões jurídicas deveriam então ser resolvidas de acordo com os estatutos comunais, e se o estatuto fosse ausente caberia a resolução de acordo com o "direito romano".
} 
Na concepção do autor português, as normas de direito romano não se caracterizariam então pela abstração, não garantiriam a comunicação jurídica entre as grandes praças comerciais europeias e não conseguiriam inverter o anti-individualismo dos direitos medievais europeus (até porque o individualismo não é uma característica do direito romano) (HESPANHA, 2009, p. 145).

As causas de recepção do "direito romano" estariam então em outros planos e seriam concernentes à: convicção de unidade política e caráter universal trazido pelo Império; ter fontes muito mais completas e sofisticadas do que a dos direitos germânicos alto-medievais e dos direitos locais; a casuística romana cobrir a generalidade das situações práticas; ter doutrina sobre os casos explicando e justificando as soluções propostas; elaboração de argumentos gerais que serviam como linhas de orientação do saber jurídico, dando coerências as soluções casuísticas (HESPANHA, 2009, p. 145).

O "direito romano" apresentava-se então não apenas como uma imposição política, mas como um conjunto de regras e casos que apresentavam soluções razoáveis e convincentes para a generalidade de problemas práticos enfrentados no período medieval. A recepção de modelos jurídicos romanos ocorreria, portanto, por uma escolha política aceita pela sua razoabilidade, muito mais do que pela correspondência às aspirações das necessidades econômicas e comerciais de abstração do período medieval (HESPANHA, 2009, p. 146).

O confronto entre as duas concepções denota, portanto, diferentes fundamentos e a particular evidenciação de conotações humanísticas ou políticas para a valorização dos textos romanos e o impulso para a tradição romanística. Tradição essa que a partir de então é evidenciada, devido à autoridade atribuída ao Corpus Iuris Civilis, como fonte primária e posteriormente secundária de muitas experiências jurídicas europeias.

\section{Conclusão}

A pluralidade e a dinâmica da tradição romanística no regime das fontes do direito evidenciam a existência de concepções diversas do di- 
reito, bem como seus reflexos na prática e na vivência social (VILLEY, 2009, p. 90). As continuidades e as descontinuidades culturais refletem-se, portanto, no regime das fontes do direito, denotando a importância de seu estudo.

Nesse contexto, evidenciou-se que os textos de direito romano e da tradição romanística, como fonte do direito, sofreram mudanças de status diante da crescente regulação jurídica das relações sociais por meio dos usos e costumes germânicos, das normas positivadas, da influência da filosofia e da política da Igreja e do Sacro Império Romano Germânico.

O papel da tradição romanística, como fonte do direito, ganhou espaço por meio dos costumes e concepções de direito da população de cultura romanizada e da omissão das regras fruto da experiência jurídica bárbara. Observou-se então a sua atuação em um plano de influência "formal" no regime das fontes do direito, representando a concepção de fonte primária nas regiões itálicas que permaneceram fiéis à Bisâncio e subsidiária naquelas em que houve o rompimento com o império. Como consequência, nas regiões que permaneceram sob a autoridade romanizada sobreviveu o estudo dos textos de direito romano, permitindo posteriormente a continuidade entre as antigas escolas imperiais de direito e as grandes escolas italianas que se afirmaram durante o século XII. Nas terras germanizadas, porém, houve a fragilização do conhecimento dos textos de direito romano, dificultando e escasseando o seu uso.

Em paralelo à dinâmica do regime das fontes do direito, que atribuiu diferente status à tradição romanística, como uma dentre as fontes "formais", como a lei e o costume; ocorre a sua influência "informal", fazendo-se presente de forma interna aos institutos jurídicos, transmitindo elementos de noções romanas às instituições jurídicas locais e posteriormente presentes nas ordenações, consolidações e códigos. Em paralelo, pode-se observar também a tradição romanística como modelo na composição de novos sistemas jurídicos, do ponto de vista sistêmico. O direito romano, por meio da tradição romanística, participa, portanto da experiência jurídica medieval em diferentes, muito embora indissociáveis modos de construir o direito. 
A conotação jurídica e a política atribuída aos textos de direito romano e à tradição romanística, implicou, portanto no seu reconhecimento como fonte primária ou subsidiária nas diferentes experiências jurídicas abordadas.

A influência da tradição romanística estende-se pela modernidade, mesmo com a afirmação do Estado e do poder do soberano. A importância dos textos de direito romano e da tradição romanística, no que concerne às experiências jurídicas, não deve ser condicionada, portanto, ao debate sobre a sua vigência, mas deve ser concebida e evidenciada como parte do processo histórico e jurídico que permitiu a formação dos ordenamentos hodiernos e ainda se faz vivo dentro desses.

\section{Referências}

AUGÉ, Guy. Apresentação: Michel Villey, história e filosofia, história de uma filosofia. In: VILLEY, Michel. A formação do pensamento jurídico moderno. Tradução de Claudia Berlinder. São Paulo: Martins fontes, 2009. p. XIII-LXXIII.

BRUNNER, Heinrich. Zur Rechtsgeschichte der römischen und germanischen Urkunden. Berlin: Weidmann, 1880.

CALASSO, Francesco. Medio evo del diritto. Milano: Giuffrè, 1954.

CATALANO, P. La religione romana internamente. Il punto di vista giuridico. Studi e materiali di Storia delle religioni, [S.l.], v. LXII, 1996.

DANIEL-ROPS, Henri. A igreja das Catedrais e das Cruzadas. 2. ed. Tradução de Emérico da Gama. São Paulo: Quadrante, 2011.

DAVID, René. L'originalité des droits de l'Amerique Latine: Le Droit Comparé. Droits d'hier, Droits de demain. Paris: [s.n.], 1982.

DE CAPITANI, Franco. II "De libero Arbitrio" di S. Agostino. Milano: Vita e Pensiero, 1994.

FALASCHI, Pier Luigi. Edictum Theodorici Regis Italiae. Milano: Giuffrè, 1966. 
FIORAVANTI, Maurizio. Costituzionalismo. Roma-Bari: Laterza, 2009. GARZÓN, Fabio Espitia. Historia del Derecho Romano. 2. ed. Bogotá: Universidad Externado de Colombia, 2006.

GAUDEMET, Jean. L'Église dans l'empire romain. Paris: Sirey, 1958. GROSSI, Paolo. L'ordine giuridico medievale. Roma-Bari: Laterza, 2002.

GROSSI, Paolo. Primeira Lição sobre direito. Trad. Ricardo Marcelo Fonseca. Rio de Janeiro: Forense, 2008.

HEGEL, G. W. F. Lezioni sulla filosofia della storia III. Trad. G. Calogero C. Fatta. Firenze, 1963.

HESPANHA, António Manuel. Cultura jurídica européia: síntese de um milénio. Florianópolis: Fundação Boiteux, 2009.

LE GOFF, Jacques. As raízes medievais da Europa. Petrópolis: Vozes, 2007.

MARONGIU, Antonio. Le privilegium scholasticum de Frédéric Barberousse et son application. Cahires de civilisation médiévale, [S.l.], v. 15, p. 295-301,1972. Disponível em: <http://www.persee. $\mathrm{fr} / \mathrm{web} / \mathrm{revues} / \mathrm{home} / \mathrm{prescript} /$ article/ccmed_0007-9731_1972_ num_15_60_1928>. Acesso em: 4 abr. 2015.

MARUOTTI, Laura S. La tradizione romanistica nel diritto europeo. Torino: Giapichelli, 2001.

MATTEUCCI, Nicola. Organización del poder y libertad. Historia del constitucionalismo moderno. Madrid: Editora Trotta, 1998.

MORRIS, Colin. The discovery of the individual 1050-1200. Toronto: University of Torornto Press, 2004.

MORTARI, Vincenzo Piano. Il problema dell'interpretatio iuris nei commentatori. In Annali di Storia del Diritto, 1958.

MUSSELLI, Luciano. Storia del diritto canonico. Torino: Giappichelli, 1992. 
ORESTANO, Riccardo. Introducción al estudio del derecho romano. Trad. y notas: Manuel Abellán Velasco Madrid, 1977.

ORESTANO, Riccardo. I fatti di produzione normativa dell'esperienza giuridica romana. Torino: Giappichelli, 1967.

PADOA SCHIOPPA, Antonio. História do Direito na Europa: da Idade Média á Idade Contemporânea. São Paulo: WMF Martins Fontes, 2014. RASI, Piero. La legislazione giustinianea ed il c.d. Edictum theodorici. Studi in onore di Pietro de Francisci, Milano, Giuffrè, v. IV, 1956. REPOSO, Antonio. Fonti del Diritto. In: MORBIDELLI, Giuseppe et al . Diritto pubblico comparato. 3. ed. Torino: Giappichelli, 2009.

ROSSATTO, Noeli Dutra. Lei e Direito em Agostinho e Tomás de Aquino. In: GELAIN, Itamar L. (Org.) Uma introdução à filosofia do direito. Ijuí: Ed. Unijuí, 2015. p. 45-62.

SALGADO, Karine. A filosofia da dignidade humana: por que a essência não chegou ao conceito? Belo Horizonte: Mandamentos, 2011. SANTO AGOSTINHO. De libero arbitrio. Milano: Vita e Pensiero, 1994.

SANTO AGOSTINHO. La città di Dio. Roma: Città Nuova Editrice, 2000 .

SANTO AGOSTINHO. Contra Faustum. Oeuvres complètes de Saint Augustin. T. XXV. Paris: Librairie de Louis Vivès, èditeur, 1870. Disponível em: $<$ http://gallica.bnf.fr/ark:/12148/bpt6k6543185w.r=S $+\mathrm{A}$ ugustinus + Hipponensis $\% 2 \mathrm{C}+\mathrm{Contra}+$ Faustum.langPT $>$. Acesso em: 15 jun. 2015.

SCHULZ, Fritz. History of Roman legal science. Oxford: Oxford University, 1953.

SPIAZZI, Raimondo. Enciclopedia del pensiero sociale cristiano. Bologna: Edizioni Studio Domenicano, 1992.

SURGIK, Aloisio. Gens gothorum: as raízes bárbaras do legalismo dogmático. Curitiba, Libro y Cultura, 2002. 
TALAMANCA, Mario. Istituzioni di diritto romano. Milano: Giuffrè, 1990.

VISMARA, Giulio. El Edictum Theodorici. Estudios visigóticos, I, Roma y Madrid, 1956.

VILLEY, Michel. O direito e os direitos humanos. São Paulo: M. Fontes, 2007.

VILLEY, Michel. A formação do pensamento jurídico moderno. São Paulo: Martins Fontes, 2009.

Luciene Dal Ri é professora do curso de graduação em Direito e do Programa de Mestrado e Doutorado em Ciência Jurídica da Universidade do Vale do Itajaí, doutora em Direito Civil-Romanístico pela Università degli Studi di Roma "La Sapienza" (Itália) e mestre em Estudos Medievais pela Pontificia Università Antonianum (Itália).

E-mail: luciene.dalri@univali.br.

Endereço profissional: Universidade do Vale do Itajaí, Rua Uruguai, n. 458, Centro, Itajaí, SC - 88302-202. 